\title{
O CONGRESSO, OS ANAIS E A HISTORIOGRAFIA APONTAMENTOS SOBRE I CONGRESSO INTERNACIONAL DE HISTÓRIA DA AMÉRICA (1922)
}

\author{
CONGRESS, ANALYSIS AND HISTORIOGRAPHY \\ Notes on I International Congress of American History (1922)
}

José Lúcio Nascimento Júnior*

Resumo: O presente artigo examina o I Congresso Internacional de História da América, realizado entre 08 a 15 de setembro de 1922, tendo como instituição promotora o Instituto Histórico e Geográfico Brasileiro. Parte do exame dos anais do Congresso publicados em 1925 como Edição Especial da Revista do Instituto Histórico para apresentar as atividades que ocorrem o longo do mesmo. Dividido em três partes, inicia com apontamentos obre a disciplinarização da história; segue demonstrando alguns eventos que membros do Silogeu participaram entre 1870-1930, demonstrando como eles influenciaram na realização do mesmo, que é apresentado na terceira seção. Apresenta conclusões provisórias, por se tratar de pesquisa de mestrado em andamento, sublinhando a importância deste tipo de fonte para o estudo pesquisa histórica.

Palavras-Chave: História dos Intelectuais; História da Historiografia; IHGB.

Abstract: This article examines the First International Congress of History of America, held from 08 to 15 September 1922, having as promoting institution the Historical and Geographic Institute. Part of the examination of the proceedings of the Congress published in 1925 as a Special Edition of the Historical Institute Magazine to present the activities that take place throughout the same. Divided into three parts, beginning with Obre notes the disciplining of history; follows demonstrating some events that Silogeu members participated between 18701930, showing how they influenced the realization of the same, which is presented in the third section. It presents provisional findings because it is ongoing master's research, stressing the importance of this type of source for the study historical research.

Keywords: History of Intellectuals; History of Historiography; IHGB.

\footnotetext{
* Mestre em História (PPGH-UERJ) e Graduado em História (UNISUAM). Professor de História da América (Faculdade de História - UNISUAM). Autor de capítulos de livros e artigos em revistas especializadas.
} 


\section{Introdução}

A prática de realizar Congressos de História é anterior a formação do campo disciplinar universitário. As universidades europeias surgiram na Idade Média, mas os cursos universitários de História remontam apenas ao século XIX. Isso, todavia, não impediu que se organizassem associações e institutos que produziam conhecimento histórico antes da formação do campo nas universidades. Na Alemanha, na França e na Inglaterra os primeiros cursos de História que surgiam criavam suas revistas para se diferenciar das produzidas antes da universitarização do conhecimento histórico, assim como passariam a realizar eventos, tais como congressos.

No caso brasileiro, porém, foi apenas na década de 1930 que surgiram os primeiros cursos universitários de História. Primeiro na Universidade de São Paulo (USP), em 1934, e, no ano seguinte, na Universidade do Distrito Federal (UDF). Isto não significa que alguns contornos da disciplinarização não pudessem ser percebidos antes da formação do campo universitário. Considerando o período da Primeira República (1889-1930), podemos observar que o Instituto Histórico e Geográfico Brasileiro (IHGB) realizou um conjunto de ações para marcar como se deveria ser produzido o conhecimento histórico no Brasil.

Neste período, em diálogo com os principais centros de produção do conhecimento histórico na Europa e nas Américas, membros do IHGB participaram de eventos em diversos países, além de os organizarem no Brasil. O I Congresso de História Nacional, em 1914, e o I Congresso Internacional de História da América, em 1922, foram realizados pelo Instituto Histórico e dispõem de inúmeras fontes de pesquisa que os tornam acessíveis para quem se interessa em pesquisar a História dos Intelectuais e da Historiografia. Dentre o conjunto de fontes disponíveis podemos citar os anais do congresso que, geralmente, são publicados após a realização dos congressos.

O objetivo deste artigo consiste em demonstrar como foi o I Congresso Internacional de História da América, realizado entre 08 a 15 de setembro de 1922, tendo como instituição promotora o Instituto Histórico e Geográfico Brasileiro. Para tanto, os anais publicados pelo Instituto Histórico se constituem fontes indispensáveis para quem visa estudar o congresso em si e as possíveis redes que foram criadas ou se solidificaram ao longo dele. Ao contrário dos congressos atuais, onde se publicam apenas os resumos e os textos apresentados, após os 
congressos o IHGB publicavam junto com os textos apresentados: as atas de reuniões preparatórias, o regulamento, as atas das seções realizadas e os pareceres dados aos trabalhos que foram apresentados.

Para cumprir o objetivo proposto, inicialmente faz-se alguns apontamentos sobre a disciplinarização; em seguida, apresenta-se alguns dos eventos que membros do IHGB participaram entre 1870 a 1930; para, na terceira seção, apresentar-se como foi realizado o I Congresso Internacional de História da América e como as fontes auxiliam no estudo do mesmo. Por ser fruto de pesquisa de mestrado em andamento, este artigo apresenta resultados parciais, mas que podem auxiliar outros pesquisadores que se dedicam ao estudo da História dos Intelectuais e da Historiografia.

\section{Apontamentos sobre formação do campo disciplinar}

Para José Carlos Reis existiram três formas de buscar o paradigma científico na passagem do século XIX para o XX. Estes paradigmas seriam: (i) o Rankeano, onde a história buscaria se aproximar do modelo de ciência proposto pelas ciências naturais; (ii) o de Diltheyan, que propunha descobrir o que havia de específico no conhecimento histórico que o torne uma ciência diferente das ciências naturais; e (iii) o marxista, que defende que o conhecimento histórico deveria ser relacionado a sua realidade social, a práxis. Estas formulações são datadas, resultam da busca de cientificidade que a História buscou a partir do século XIX, em especial na segunda metade (REIS, 2011).

Estas formulações poderiam ser suficientes para que o problema que analisamos neste artigo fosse resolvido. A disciplinarização da História seguiria um dos paradigmas apresentados e a partir deles buscaríamos reconstruir a História da disciplina. Contudo, a história, enquanto experiência vivida tem uma variável incontrolável, o ser humano. Esta variável faz com que os processos históricos sejam únicos e não possam ser repetidos. O que, por sua vez, gera a possibilidade de se realizar novos estudos a partir de diferentes perspectivas.

Para François Hartog, os Regimes de Historicidade são formas de se conceber a relação entre passado-presente-futuro que uma sociedade estabelece como forma para tratar o seu e do seu passado (HARTOG, 2014). Logo, a historicidade seria a forma como as sociedades lidam com a experiência do tempo; estas formas passaram por alterações ao longo da história da 
Humanidade. Tais categorias, por sua vez, nos auxiliam a pensar o ofício do historiador. Assim, antes da busca de cientificidade que marcam os três paradigmas supracitados, que para Hartog (2014) estariam no Regime Moderno de Historicidade, podemos encontrar o regime por ele denominado Historia Mgistra Vitae ou História Mestra da Vida.

A ideia da Historia Mestra da Vida consiste no regime de historicidade onde o passado servia de modelo para o presente e para a construção do futuro. Este regime estaria ligado à produção historiográfica até século XVIII. Hartog buscou em Reinhart Koselleck as características de regime de historiografico e as experiências do tempo que marcam a mudança do Regime da História Mestre da Vida para o Regime Moderno, observando que estas se modificaram a partir do final do século XVIII, com a Revolução Industrial (1760) e a Revolução Francesa (1789). Hartog vê em Chateaubriand uma pessoa que viveu a mudança do Regime da História Mestra da Vida para o Regime Moderno de Historicidade (HARTOG, 2014).

Para Koselleck (2006) é impossível analisar o trabalho do historiador sem observar as categorias por ele utilizadas. Neste sentido, ao analisar a produção historiográfica do IHGB na primeira metade do século XIX,' Manoel Salgado Guimarães (2011) destaca que a História produzida pelo IHGB era ao mesmo tempo Mestre da Vida e iluminista, fazia uma biografia do Estado e da História retirava os exemplos que precisava para ensinar e transmitir seu projeto. Este modelo estava presente na proposta de escrita de História feita por Von Martius em 1844 e que seria seguido por Francisco Adolfo de Varnhagem ao escrever sua História Geral do Brasil.

Guimarães (2006) realizou uma comparação entre a produção do IHGB e a da Revista "O Patriota". Ele destaca que para o editor da revista o passado deveria ser ordenado para ajudar a compreender o futuro. Tal posição foi defendida por Januário da Costa em seu discurso na fundação do IHGB. Em ambos a função da História era ensinar e julgar a partir do passado. Contudo, partindo das palavras de Manoel Luís Salgado Guimarães, defendemos uma posição diferente da de François Hartog. Estes regimes de historicidade não se sucedem, eles podem coexistir em um mesmo local ou ao mesmo tempo.

Para o caso francês, Gerard Noiriel (1998) apresenta que a formação da disciplina ocorre no último quartel do século XIX. Neste momento, a III República francesa que buscava se legitimar no poder auxilia e promove a formação do historiador no espaço universitário. Se o Instituto Histórico de Paris e os clubes literários eram espaços de sociabilidade e de produção 
intelectual de pensadores ligados a Monarquia e a Igreja Católica, as universidades passariam a contar em seus quadros com novos intelectuais republicanos e protestantes.

A profissionalização do historiador, na França, ocorreu com a formação da universidade republicana e a instituição dos princípios científicos para o campo. Tal ação teve como consequências: (i) aproximar a escola da universidade por meio da pesquisa científica; (ii) transferiu-se para a universidade os estudos das técnicas de pesquisa; e (iii) anexou-se os institutos de pesquisa a Sorbonne. Neste caminho as revistas científicas marcariam o novo momento que a história vivia: o uso do método científico. Elas se constituiriam em um espaço ao mesmo tempo de divulgação dos conhecimentos científicos e de julgamento por parte dos pares, formando redes de sociabilidade (PROST, 2014).

De acordo com Lúcia Guimarães (2007a), os membros da Escola Palatina participavam de eventos internacionais desde a criação desta instituição. No Congresso de Ciências Históricas de Veneza, em 1881, os membros do IHGB receberam um prêmio por causa da qualidade da Revista do Instituto Histórico dentro do cenário internacional. Este prêmio também congratulava os historiadores brasileiros pela qualidade dos mapas expostos ao longo do evento. Percebe-se, então, que o uso dos métodos científicos, no caso brasileiro, não veio acompanhado do surgimento de universidades, mas, sim, praticados pelos membros do Instituto, que na primeira metade do século XIX utilizavam o modelo da Historia Mestra da Vida e que desde do século XIX não estavam alheios as produções cientificas na Europa.

Para Manoel Guimarães (2003), a escrita da História a partir de Leopold Von Ranke iria se assentar no uso de métodos científicos. Ao longo do século XIX a cultura histórica articulou de uma maneira nova a relação entre passado e presente. Esta História científica trouxe consigo um novo sentido de historicidade, o Regime Moderno, tal como definido por Hartog (2014). No caso brasileiro, a História Científica já podia ser observada na passagem do século XIX para o XX. O IHGB seria o lócus privilegiado para este tipo de produção. Porém, ao contrário do caso francês, no Brasil o uso do método científico não veio acompanhado da formação universitária, que apenas iria se iniciar na década de 1930 (GUIMARÃES, 2007a; GOMES, 2009; FERREIRA, 2013).

Os Congressos de História realizados entre 1870 e 1930 são exemplares para analisar a busca pela cientificidade dentro do campo. Estes foram eventos que reuniram letrados que realizavam o mesmo ofício para que seja apresentado suas pesquisas e o as transformações no campo disciplinar. O I Congresso Internacional de História da América, realizado no Rio de 
Janeiro em 1922, promovido pelo IHGB, pode ser utilizado como estudo de caso. Por ser um evento que reuniu historiadores e letrados diversos, este possibilita observar como estavam os contornos de formação e de institucionalização do campo disciplinar no Brasil, além das redes de sociabilidade que os historiadores brasileiros possuíam primeiro quartel do século XX. Tal situação torna-se latente ao observamos que Afonso de E. Taunay e Alfredo Ellis Jr. que seriam professores da Universidade de São Paulo na década de 1930 participaram e apresentaram memórias neste Congresso.

Os historiadores brasileiros, mesmo antes da institucionalização da profissionalização do historiador no Brasil na década de 1930, não estavam alheios a produção historiográfica e científica realizada nos principais centros de produção na Europa e nos Estados Unidos (GUIMARÃES, L., 2011; GUIMARÃES, M. 2006; 2011; GOMES, 2009; OLIVEIRA, 2013; IUMATTI; VELLOZO, 2014). Ainda na primeira metade do século XIX, Jean Baptista Debret possibilitaria o acesso do Araújo de Porto Alegre ao Instituto Histórico Francês, criado em 1834. Além disso, o ganhador do concurso realizado pelo IHGB, na primeira metade do oitocentos para saber como se escreveria a História do Brasil, Von Martius, naturalista austríaco que veio para o Brasil junto com a Missão Artística Austríaca que desembarcou em terras brasílicas em 1817 junto com Dona Maria Leopoldina, esposa de D. Pedro I, era alemão e estava atendo as transformações no fazer histórico (OLIVEIRA, 2013).

Alguns contornos de disciplinarização da História já eram perceptíveis nos primeiros anos da República Brasileira. A constituição de 1891 previa que os estados passariam a ter mais autonomia de ação frente a disputas sobre território, ao que ocorria antes no império. Neste bojo estava a discussão sobre os limites e posses dos territórios entre os estados. Assim, os conhecimentos históricos e geográficos eram utilizados para comprovar a posição de uma das partes em questões de terras; este por sua vez deveria se assentar em bases científicas reconhecidas por seus pares.

Entre 1891 e 1930, muitos dos Institutos Históricos e Geográficos e Museus estaduais foram criados. Os conhecimentos históricos e geográficos eram mobilizados como forma de justificar ações políticas, fazendo com que os IHG e os museus passassem a ter um papel decisivo por proporcionar um parecer técnico para questões políticas de sua época. A base para a cientificidade era buscada em dois movimentos, a pesquisa empírica e nas ciências produzidas nos principais centros de produção do conhecimento na Europa. O governo republicano passou 
a financiar expedições de pesquisas em vários estados (IUMATTI; VELLOZO, 2014; SCHWARCZ, 2003).

Mesmo tendo sido financiado pelo governo imperial, nos primeiros anos da República ocorreria a aproximação entre o governo republicano e o IHGB. Esta aproximação possibilitou que alguns projetos do Instituto fossem financiados pelo governo republicano, para tanto os governos republicanos buscavam legitimar o novo regime a partir da História escrita no Instituto. A própria noção de Golpe ou Proclamação foi largamente discutida dentro do Instituto, havendo membros que defendiam uma ou outra opção (SOUZA, 2015). Estas posições, por sua vez, eram sustentadas com base na pesquisa documental, juntando o caráter experimental, monográficos e baseados nos estudos dos principais centros de pesquisas na Europa e EUA.

O trabalho de entrada no IHGB Pedro Augusto Carneiro Lessa, historiador e advogado, pode ser utilizado como exemplo de análise. Ele referenciou seu trabalho em diversos intelectuais que estavam produzindo conhecimento histórico e científico na virada do século XIX para XX. Dentre eles, o Lessa se baseia no livro Introduction aux Études Historiques publicado em 1898 por Charles Langlois (1863-1929) e Charles Seignobos (1854-1942). Em Langlois e Seignobos, Lessa buscava o rigor metodológico para conduzir sua pesquisa, tal como o caráter científico da época preconizava. Além destes, constata-se a referência a trabalhos de Fustel de Coulanges e Oliveira Martins, além de pensadores como Schopenhauer, Maquiavel e Stuart Mill (GOMES, 2009).

\section{O IHGB e a prática de participar de congressos}

O Instituto Histórico e Geográfico Brasileiro foi criado em 1838 e no ano seguinte um de seus membros já estava participando de um Congresso Internacional de História na Europa. Luiz Moutinho Alvares e Silva participou do Congresso de Ciências Históricas realizados na Itália. A prática de enviar sócios para congressos e eventos internacionais se manteve ao longo do século XIX e da primeira metade do século XX. Mesmo com a virada de regime político no Brasil, em 1889, houve participação na Exposição Universal de Paris, naquele ano, que foi realizada em comemoração ao primeiro centenário da Revolução Francesa; além deste, também 
participaram, em 1892, da Exposição Columbiana realizada em Chicago nos Estados Unidos, contando com apoio do Governo Republicano.

Nos primeiros anos dos novecentos, Manuel Oliveira Lima foi enviado pelo Instituto para participar do XVI Congressos de Americanistas em Viena, na Áustria. Ao retornar deste congresso proferiu uma conferência no IHGB em 1913, intitulada $O$ atual papel do Instituto Histórico, onde questionava a não ocorrência de eventos como esse no Brasil. Nas palavras de Lúcia Guimarães, tem-se que:

Os ventos do culto à nacionalidade também sopravam pelos lados do Instituto Histórico. Afinal, dentre as ligações do catecismo cívico, sobressai-se o estudo da história pátria. Tanto que, em 23 de abril de 1913, o historiador e diplomata Manuel de Oliveira Lima pronunciou uma conferência, que obteve grande ressonância entre os letrados e políticos, intitulada "O atual papel do Instituto Histórico". [...] Tarefas pedagógicas de assinalado serviço a causa nacional, no entender do conde de Afonso Celso, então presidente do Instituto, figura reconhecida como chefe venerável do nacionalismo brasileiro (GUIMARÃES, 2007a, p. 81).

Além da participação de Oliveira Lima neste evento, não podemos deixar de sublinhar a ação de outro importante membro do Instituto em eventos internacionais. O Barão do Rio Branco, que foi o correspondente do IHGB no Congresso de Americanistas de Luxemburgo em 1878, se tornaria ministro das Relações Exteriores e presidente da Escola Palatina entre 1902 e 1912, ano de sua morte. Durante os anos em que esteve à frente do Ministério das Relações Exteriores, a política externa brasileira mudaria, ao invés de olhar apenas para a Europa, o Brasil passaria participar de Conferências Pan-americanas, o que não acontecia nos tempos do Império.

O próprio Simon Bolívar convocou o Congresso do Panamá em 1826 com o objetivo de criar uma confederação entre as jovens nações latino-americanas. Este congresso, contudo, não logrou êxitos. Apenas com o Manifesto do Partido Republicano, em 1870, foi que o Brasil se aproximou dos EUA e da América Latina. Assim, quando da convocação do I Conferência dos Estados Americanos realizada entre outubro de 1889 e abril de 1890 em Washington, o Brasil enviou participantes. Nesta Conferência ficou nítida a oposição entre os interesses estadunidenses e argentinos, e que um acordo entre os países americanos seria um longo caminho a se construir. Após as conferencias nos EUA, foram realizadas outras três, sendo a 
segunda no México em 1901/02, a terceira no Rio de Janeiro em 1906 e a quarta em Buenos Aires em 1910.

A III Conferência Internacional Americana foi realizada no Rio de Janeiro entre 23 de julho e 27 de agosto de 1906. Todos os países da América foram convidados, exceto o Canadá. Nessa conferencia, houve a participação de representantes dezenove países. Mesmo atendendo a questões levantadas por quase todos os países representados, neste encontro os representantes brasileiros evitaram, ao máximo, temas que fossem controversos, dentre eles acordos multilaterais. Tal postura de evitar grandes embates pôde ser vista tanto no Barão do Rio Branco quanto no secretário de Estado dos Estados Unidos Elihu Root (BUENO, 1997).

$\mathrm{Na}$ análise que fez do memorial da III Conferencia, Bueno observou que a Argentina era a maior opositora das propostas de Pan-Americanismo realizadas pelos Estados Unidos. Os portenhos tinham uma posição comercial mais isolada no contexto de relações comerciais da América, tendo o seu fluxo comercial ligado a Europa. Havia uma concorrência entre os argentinos e os estadunidenses no comércio de trigo desde 1870, o que fazia com que os primeiros fizessem acordos bilaterais com o Brasil, mercado que estava em franca expansão. Se do ponto de vista econômico a Conferencia de 1906 trouxe pouco dividendos econômicos para o Brasil, esta pôde aproximar ainda mais o Brasil dos EUA. Além disso, a ação do Barão do Rio Branco foi uma mostra de seu prestigio político ao trazer para o Rio de Janeiro antes de Buenos Aires a Conferência, mostrando que as relações entre o Brasil e os EUA eram intensas desde a passagem do século XIX para o XX (BUENO, 1997). Essa oposição entre argentinos e estadunidenses também foi vista no I Congresso Internacional de História da América, em 1922, como veremos a seguir.

\section{O Congresso Internacional de História da América}

Em 1908, ainda sob a presidência do Barão do Rio Branco, houve a tentativa de se fazer um primeiro congresso internacional reunindo pesquisadores brasileiros e portugueses. Este projeto não se realizou devido ao assassinato do monarca português D. Carlos que estava com visita marcada ao Brasil. Nas duas décadas seguintes, o nacionalismo se efervesceu e o IHGB realizou dois grandes congressos. O I Congresso de História Nacional, em 1914, e I Congresso 
Internacional de História da América realizado dentro das comemorações do Centenário da Independência, ocorrido no Rio de Janeiro em 1922 (GUIMARÃES, L. 2005; 2007a; 2007b).

Em 1913, havia a ideia de se realizar um Congresso de Historiadores, já que a tentativa de 1908 acabou sendo frustrada e se aproximava as Comemorações do Centenário da Independência. Como bem apresentado por Lúcia Guimarães (2005; 2007a; 2007b), em 1914, realizou-se o I Congresso de História Nacional organizado pelo IHGB. Ao final deste houve a proposta de se realizar o Congresso Internacional de História da América durante as comemorações do Centenário da Independência em 1922, integrando não apenas letrados brasileiros como americanos e de países da Europa que mantiveram relações com a América no período colonial.

No instituto a ideia de se comemorar o primeiro Centenário da Independência não era nova, já havia sido levantada pelo conselheiro Manuel Francisco de Correia, em 1898, tendo deixado após sua morte dividendos para este fim. Foi João Mendes e Afonso Arinos que trouxeram, em 1903, para o Instituto a ideia de se fazer um Congresso de História Nacional, já com o objetivo de avaliar a situação dos estudos históricos no Brasil. Nesse Congresso de História Nacional Afonso Arinos e Max Fleuiss, então secretário-geral do IHGB, sugeriram a realização do Congresso Internacional de História da América dentro das comemorações do Centenário, alinhando o Instituto as ações iniciadas pelo Barão do Rio Branco, de reorientar a posição do Silogeu para olhar também para a América.

Isto não significou que os contatos com a Europa seriam totalmente rompidos. Tanto o I Congresso de História Nacional, realizado em 1914, quanto o Congresso Internacional de História da América, realizado em 1922, tiverem sua organização baseada nas propostas de Charles Langlois e Charles Seignobos, em Introduction aux Études Historiques. Ao Organizar as sessões do mais geral para o mais específico, houve o predomínio da História Política dentre os campos da História com mais trabalhos apresentados, os dois congressos realizados pelo IHGB no primeiro quartel do século XX, estavam em consonância com as propostas dos dois mestres franceses (GUIMARÃES, L., 2007a; 2007b).

No caso do Congresso de História da América ele era organizado em 30 seções composta por 9 subseções, tal como o apresentado pelo regulamento do congresso. As Seções e subseções estão apresentadas nas tabelas 1 e 2 . 


\begin{tabular}{|l|l|}
\hline \multicolumn{2}{|c|}{ Tabela 1 - Seções do I Congresso Internacional de História da América } \\
\hline $1^{\mathrm{a}}-$ História Geral da América. & $18^{\mathrm{a}}-$ História da República Argentina. \\
$2^{\mathrm{a}}-$ História dos Estados Unidos da América & $19^{\mathrm{a}}-$ História do Uruguai. \\
do Norte. & $20^{\mathrm{a}}-$ História de Cuba. \\
$3^{\mathrm{a}}-$ História do México. & $21^{\mathrm{a}}-$ História da República Dominicana. \\
$4^{\mathrm{a}}-$ História da Guatemala. & $22^{\mathrm{a}}-$ História do Haiti. \\
$5^{\mathrm{a}}-$ História de Honduras. & $23^{\mathrm{a}}-$ História do Domínio do Canadá. \\
$6^{\mathrm{a}}-$ História de S. Salvador. & $24^{\mathrm{a}}-$ História da Guyana Ingleza. \\
$7^{\mathrm{a}}-$ História da Nicarágua. & $25^{\mathrm{a}}-$ História da Guyana Hollandeza. \\
$8^{\mathrm{a}}-$ História de Costa Rica. & $26^{\mathrm{a}}-$ História da Guyana Franceza. \\
$9^{\mathrm{a}}-$ História do Panamá. & $27^{\mathrm{a}}-$ História da Colonias insulares inglesas \\
$10^{\mathrm{a}}-$ História da Colombia. & da América e de Honduras Britânica. \\
$11^{\mathrm{a}}-$ História da Venezuela. & $28^{\mathrm{a}}-$ História das Colonias insulares \\
$12^{\mathrm{a}}-$ História do Equador. & francezas na América. \\
$13^{\mathrm{a}}-$ História do Peru. & $29^{\mathrm{a}}-$ História das Colonias insulares \\
$14^{\mathrm{a}}-$ História da Bolívia. & hollandezas na América. \\
$15^{\mathrm{a}}-$ História do Brasil. & $30^{\mathrm{a}}-$ História das Colonias insulares \\
$16^{\mathrm{a}}-$ História do Paraguai. & dinamarquezas nas América. \\
$17^{\mathrm{a}}-$ História do Chile. & \\
\hline \multicolumn{2}{|l|}{ Fonte: IHGB, 1925, p. 16. } \\
\hline
\end{tabular}

\begin{tabular}{|l|l|}
\hline \multicolumn{2}{|c|}{ Tabela 2-As subseções do I Congresso Internacional de História da América } \\
\hline $1^{\mathrm{a}}$ - História Geral; & $5^{\mathrm{a}}$ - História Parlamentar; \\
$2^{\mathrm{a}}$ - História das Explorações Geográficas; & $6^{\mathrm{a}}$ - História Econômica; \\
$3^{\mathrm{a}}$ - História das Explorações Arqueológicas e & $7^{\mathrm{a}}$ - História Militar; \\
Etnográficas; & $8^{\mathrm{a}}$ - História Diplomática; \\
$4^{\mathrm{a}}$ - História Constitucional e Administrativa; & $9^{\mathrm{a}}$ - História Literária e das artes. \\
\hline \multicolumn{2}{|c|}{ Fonte: IHGB, 1925, p. 16 e 17} \\
\hline
\end{tabular}

No caso do Congresso Internacional de História da América realizado em 1922, Lúcia Guimarães aponta que a divisão das sessões seguia a proposta de organização da história tal como definida por Charles Langlois e Charles Seignobos em seu manual de história de 1898. O uso do recurso de cientificidade, por sua vez, não era uma ação pontual para os congressos, mas uma prática que aqueles que praticavam história deveriam saber. De acordo com Maria da Glória de Oliveira, Capistrano de Abreu, no primeiro quartel do século XX, direcionou críticas a alguns membros do IHGB questionando-os sobre a falta de perícia nos usos dos métodos (OLIVEIRA, 2013). A crítica, por sua vez, demonstra que havia uma ideia do que fazia ou não parte do ofício do historiador. 
Tomando como exemplo o parecer dado à memória escrita por Bernadino José de Sousa, intitulada Joanna Angelica. A primeira heroína da independência do Brasil, sendo esta a $8^{\mathrm{a}}$ tese da $1^{\mathrm{o}}$ subseção, História Geral, da $15^{\mathrm{a}}$ seção História do Brasil, nota-se que ao mesmo tempo em que o relator Alfonso Claudio destacou que o autor procedeu com um estudo "sedento da verdade documentaria, que ahi emerge, de páginas claras e estylisadas, com o bafio dos archivos e a poeira do ineditismo", mereceu críticas por "não ser inédita a these oferecida, visto que não satisfaz a exigência taxativa do art. $8^{\text {a }}$ do regimento geral, - de ser inédita a these offerecida a aproveitamento na referida publicação" (IGHB, 1925, p. 122-123).

Outro ponto em comum com a produção historiográfica francesa reside no predomínio do método de estudo e do uso de fontes documentais. A escola metódica se caracterizava tanto pelo predomínio do uso da fonte escrita, quanto pelo rigor metodológico no exame desta fonte; além disso, havia a necessidade de distanciamento temporal entre o pesquisador e o objeto pesquisa (REIS, 2011). No caso do Congresso de 1914, o recorte temporal era o fim do Primeiro Reinado em 1831; mas, no Congresso de 1922, o recorte temporal era 1870, com o fim da Guerra do Paraguai, possibilitando o exame de quase todo o período imperial, sobre o qual a maioria dos historiadores brasileiros se debruçaram (GUIMARÃES, 2005).

Entre 1914 e 1922, ocorreram algumas reuniões preliminares para organização do Congresso de História da América. Na sessão de 15 de fevereiro de 1915 foi expedida uma portaria nomeando a Comissão Executiva do Congresso de Internacional de História da América. A primeira reunião desta comissão, sendo a reunião coordenada pelo presidente perpétuo do Instituto, o Conde de Afonso Celso foi realizada em 23 de fevereiro de 1915 e se decidiu pela composição da Comissão Executiva do evento. Em 09 de agosto de 1916 seguiu, para o Ministério das Relações Exteriores, as instruções para proceder com os convites as delegações de todos os países da América e alguns outros, tais como Portugal, França, Espanha e Inglaterra.

A solenidade de abertura foi no dia 08 de setembro de 1922 e contou com personalidades ilustres, tais como o Dr. Epitácio Pessoa, membro do IHGB, presidente solene do Congresso e presidente do Brasil naquele momento, Charles Evans Hughes, secretário d'Estado dos Estados Unidos da América, sir. John Tilley, embaixador da Inglaterra, Eufrásio Losa, embaixador da Argentina, além de outras personalidades de vários países do continente americano. Entre os dias 9 e 14 de setembro realizaram-se as seções e subseções previstas no Congresso, além de visitas ao Jardim Botânico e Museu Nacional no dia 10 de setembro; no dia 12, foram visitados 
o Senado Nacional, Câmara dos Deputados e Biblioteca Nacional; no dia 13, foram visitados o Supremo Tribunal Federal e a Escola Nacional de Belas Artes ${ }^{1}$.

As duas sessões plenas ocorreram nos dias 12 e 14 de setembro, sendo que na primeira ocorreram uma série de discursos dentre os quais o do dr. Ricardo Levene, da Argentina, o de Manuel Cícero e o do Conde de Afonso Celso. Ainda nessas sessões foi aprovada proposta para a elaboração de um livro de História Geral da América escrito em conjunto com os representantes de todos os países presentes. A sessão de encerramento foi realizada no dia 15 de setembro de 1922, iniciada às 16 horas, onde houve a homenagem a José Bonifácio, chamado de $O$ Patriota; nesse dia houve ainda um Banquete oferecido no salão da Associação dos Empregados do Comércio. O fim do congresso se seguiu de uma viagem a São Paulo, entre 16 a 20 de setembro.

Os anais apenas seriam impressos pela editora Impressa Nacional, em 1925, e publicados como edição especial da Revista do IHGB. Contando com nove volumes, que totalizam mais de 4 mil páginas, esta fonte nos permite acessar tanto a produção historiográfica do congresso, quanto outras atividades nele realizadas, como as atas de reuniões preparatórias, o regulamento, as atas das seções realizadas e os pareceres dados aos trabalhos que foram apresentados. No Volume 1, são apresentadas as atas das atividades realizadas ao longo desse Congresso. Através delas é possível ter acesso a discursos proferidos, homenagens realizadas e aos pareceres dados as memórias (trabalhos) apresentados.

\footnotetext{
${ }^{1}$ Em $1^{\text {o }}$ de setembro de 1922, houve a Primeira Sessão Preparatória do Congresso. Nesta sessão Ramiz Galvão propôs que a comissão organizadora redigisse o Regimento Interno do Congresso. Neste grupo estavam os brasileiros Manuel Cícero, Tavares Lyra, Nuno Pinheiro, Solidonio Leite e o argentino Dr. Enrique Loudet. O regimento de interno foi aprovado na terceira sessão realizada a 06 de setembro. Nesta sessão foi anunciada a compra da Casa de Tiradentes, em Ouro Preto, pelo IHGB e foram eleitos os cargos de honra do Congresso. (Cf. IHGB, 1925).
} 


\section{Figura 1.}

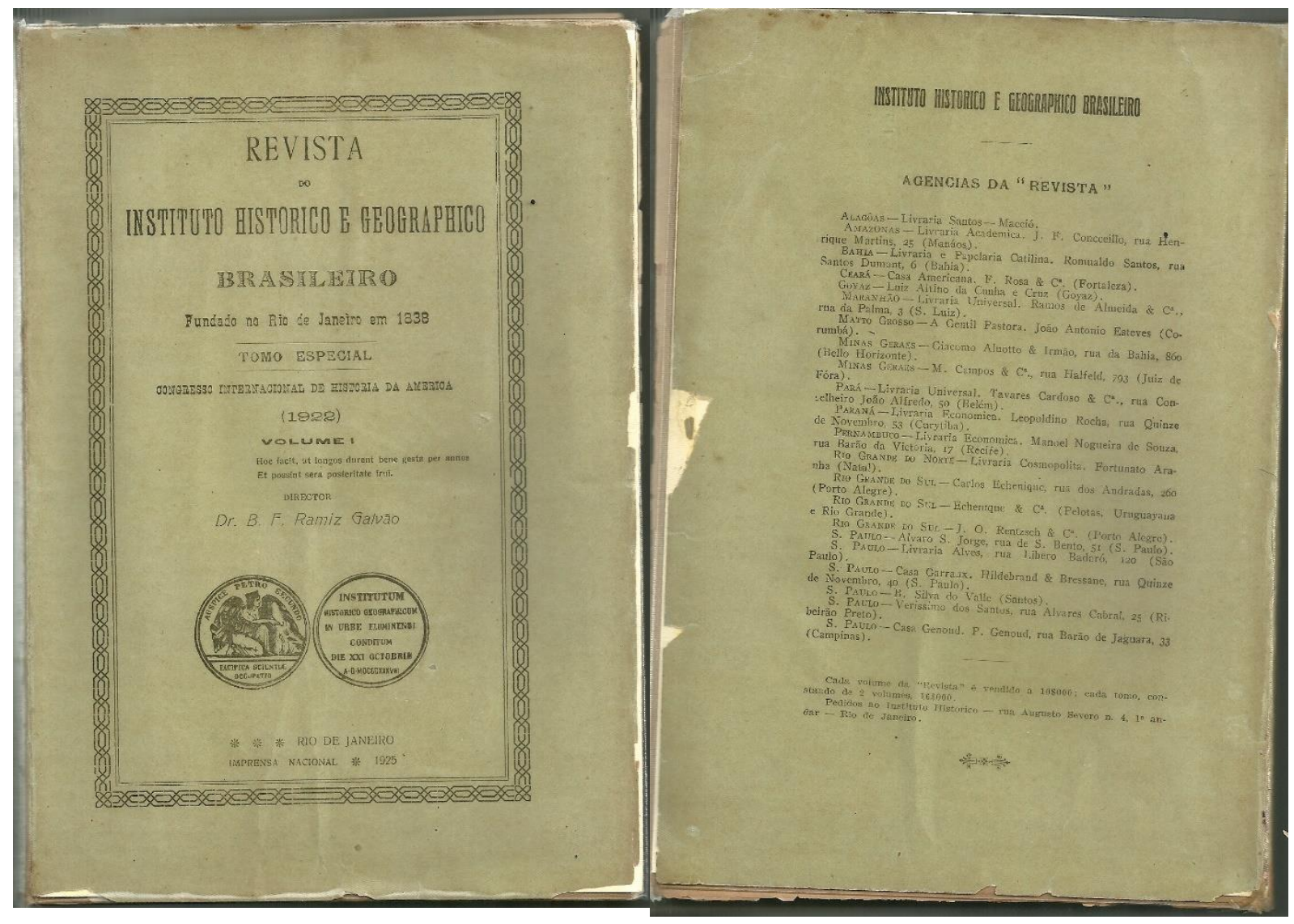

Capa e Fundo de capa da Revista do IHGB - Tomo Especial - Volume 1

Fonte: Arquivo pessoal do autor

Ao ser editado em formato de Revista, o IHGB disponibilizou os nove volumes para venda na sua livraria que fica na própria sede. Além da sede no Rio de Janeiro, no fundo da revista a indicação dos locais onde a mesma se encontrava disponibilizada para venda em outros estados. Havendo lojas em 14 dos 19 estados brasileiros existentes em 1925, percebemos que este material foi disponibilizado para diferentes partes do Brasil, além dos enviados para institutos e instituições congêneres em outros países. No está no escopo da pesquisa na qual este trabalho deriva, analisar a circulação que estes tomos tiveram, porém, cabe sublinhar que este não ficou restrito apenas a sede do IHGB no Rio de Janeiro, o que ampliava a divulgação do conhecimento histórico e da forma como produzi-lo. 


\section{Considerações finais.}

Quando se pensa em cultura escrita, muitas vezes, se relaciona com a produção de cartas, jornais, revistas e panfletos. Contudo, além destes vetores, os anais de congresso podem ser uma excelente oportunidade para quem deseja realizar pesquisas nos campos de História dos Intelectuais e/ou História da Historiografia. No caso do I Congresso Internacional de História da América, objeto de estudo da pesquisa de mestrado em andamento, os anais têm fornecido possibilidades diversas de se olhar tanto para a produção historiográfica do período quanto das possíveis relações que se criaram e ou se consolidaram a partir dele. Investir nesse tipo de fonte, a nosso ver, abra a possibilidades para diferentes abordagens teórico-metodológicas na pesquisa histórica.

Esse Congresso fez parte das comemorações do Centenário da Independência, em 1922. Contou com a presença de algumas personalidades ilustres, tais como o então presidente do Brasil, Epitácio Pessoa, que também era membro do Instituto e fora eleito presidente honorário do evento. Houve a presença de letrados de diferentes países, abrindo diversas possibilidades de estudos.

\section{Referências bibliográficas}

BUENO, C. Da Pax britânica à Hegemonia Norte-americana: o integracionaismo nas Conferencias Internacionais Americanas (1826-1906). Estudos Históricos. Rio de Janeiro: $1997, n^{\circ} .20$, p. $231-250$

FERREIRA, M. de M. A História como ofício. Rio de Janeiro: FGV, 2013.

GOMES, A. A República, a História e o IHGB. Belo Horizonte: Argvmentvm, 2009; GUIMARÃES, L. Circulação de saberes, sociabilidades e linhagens historiográficas: dois congressos de História Nacional (1914-1949). in.: GUIMARÃES, M. (org.) Estudos sobre a escrita da História. Rio de Janeiro, 2007b, p. 162-181.

\section{GUIMARÃES, L. Da Escola Palatina ao Silogeu: o Instituto Histórico e Geográfico}

Brasileiro (1889-1930). Rio de Janeiro: Museu da República, 2007a.

GUIMARÃES, L. Limites políticos de um projeto intelectual para a integração dos países do Novo Mundo: o Primeiro Congresso Internacional de História da América (1922). Topoi. Rio de Janeiro, Vol. 6, nº 10, jan.-jun de 2005, p. 192-212. 
GUIMARÃES, L. Sobre a história da historiografia como campo de estudos e reflexões. in.: NEVES, L. et. al. Estudos de Historiografia brasileira. Rio de Janeiro: FGV/FAPERJ, 2011, p. 19-35.

GUIMARÃES, M. L. A cultura histórica oitocentista e o nascimento da disciplina. Anais do XXII Simpósio Nacional de História da ANPUH. João Pessoa: ANPUH, 2003. 1 - 7.

GUIMARÃES, M. L. Entre as luzes e o romantismo: as tensões da escrita da história oitocentista. in.: GUIMARÃES, M. L. S. et. alli. Estudos sobre escrita da História. Rio de Janeiro: Sette Letras, 2006, p. 68-85.

GUIMARÃES, M. L. Historiografia e Nação no Brasil (1838-1857). Rio de Janeiro: UERJ, 2011.

HARTOG, F. Regimes de Historicidade: Presentismo e experiências do tempo. Belo Horizonte: Autêntica, 2014.

IHGB. Anais do Congresso Internacional de História da América (1922). Rio de Janeiro: Imprensa Nacional, 1925, vol. 1.

IUMATTI, P.; VELLOZO, J. C. Conhecimento, política e instituições no Brasil (1889-1934).

Reflexos, Paris, nª 2, p. 1-26, 2014. Disponível em: http://e-revues.pum.univ-

tlse2.fr/sdx2/reflexos/article.xsp?numero=2\&id_article=varia_02teixeiraiumatis-492.

Acessado em: 12/07/2016.

NOIRIEL, G. Sur La “crise” de l'Histoire. Paris: BELIN, 1998.

OLIVEIRA, L. L. Cultura é patrimônio: um guia. $3^{\text {a }}$ reimp. Rio de Janeiro: FGV, 2013;

OLIVEIRA, M da G. Crítica, método e escrita da História em Capistrano de Abreu. Rio de Janeiro: FGV, 2013.

PROST, A. Doze lições de história. $2^{\text {a }}$ Ed. Belo Horizonte: Autentica, 2014.

REIS, J. C. A História, entre a Filosofia e a Ciência. $4^{a}$ Ed. Rev. e Amp. Belo Horizonte: 2011.

SCHWARCZ, L. M. O espetáculo das Raças. São Paulo: Cia das Letras, 2003.

SOUSA, F, Revolta e proclamação como molduras da história; escrita de história e olhares para a República entre os sócios do IHGB. História da Historiografia. Ouro Preto, $\mathrm{n}^{\circ} 18$, Ago de 2015, p. 215-230. 